\title{
An assessment of the human nail plate $\mathrm{pH}$
}

S Murdan*, G Milcovich and G S Goriparthi

Department of Pharmaceutics, School of Pharmacy, University of London

*corresponding author; Tel: +44-2077535810; Fax: +44-2077535942;

sudax.murdan@pharmacy.ac.uk

Running title - measurement of nail plate $\mathrm{pH}$

Keywords: nail, pH, surface, tape stripping, washing, gender

The work described in this paper was supported by The School of Pharmacy, University of London. The authors have no conflict of interest to declare.

Address: The School of Pharmacy, University of London, 29-39 Brunswick Square, London, WC1N 1AX, UK 


\begin{abstract}
Purpose of study: To measure the $\mathrm{pH}$ of the surface of healthy nail plates.

Procedures: The surface $\mathrm{pH}$ of human fingernails and big toenails was measured in vivo using a skin $\mathrm{pH}$ meter. The influence of washing, anatomical site (fingers/toes), side (left/right), digit (digits 1-5) and gender were determined. The $\mathrm{pH}$ of the nail interior was also measured.

Results: The $\mathrm{pH}$ of the nail plate surface was around 5, with toenails having a significantly higher $\mathrm{pH}$ than fingernails. Immediately after handwashing, the nail surface $\mathrm{pH}$ increased significantly, from $\mathrm{pH} 5.1 \pm 0.4$ to $5.3 \pm 0.5$. However, this was not sustained with time, and $\mathrm{pH}$ returned to pre-washing levels within 20 minutes. Gender had an influence on unwashed, but not washed, nailplate $\mathrm{pH}$. The $\mathrm{pH}$ of the nail plate interior was lower than that at its surface.
\end{abstract}

Conclusions: It was possible to measure nail plate $\mathrm{pH}$, and baseline values are provided.

\title{
INTRODUCTION
}

The nail unit consists of the nail plate (commonly referred to as the nail), the nail bed, the nail folds, the hyponychium, and the nail matrix. The latter produces the nail plate which overlies the nail bed, and is framed and ensheathed by the nail folds and the hyponychium. The transparent nail plate is hard yet slightly elastic, curved in both the longitudinal and transverse directions, and its size, shape, thickness, surface ridging, curvature, and mechanical properties such as flexibility vary within and among individuals, with site (finger/toe), age, and other endogenous and exogenous factors such as disease states and seasons [1,2]. The nail plate is said to consist of three distinct parallel strata: dorsal, intermediate and ventral [3-5], although some researchers have divided it into only two layers: a thin hard dorsal layer and a thicker plastic ventral one [6].

Eighty to ninety layers of dead, keratinised cells [7], which are surrounded by an intercellular 'cement' (thought to consist of proteins and/or mucopolysaccharides [2]) make up the nail plate. The latter's constituents include keratins, which form its bulk $[8,9]$, water (between 5 and $30 \%,[10,11]$ ) and lipids (less than $5 \% \mathrm{w} / \mathrm{w}$ in adults) such as, cholesterol sulphate, ceramides, free sterols, free fatty acids, triglycerides, sterol and wax esters and squalene $[9,12]$. Elements such as calcium, magnesium, sodium, potassium, iron, copper, zinc, aluminium, chlorine, amongst others have also been measured in the nail plate $[13,14]$. The growing nail plate incorporates substances from its surroundings via the systemic circulation, and drugs (therapeutic and recreational), isotopes (e.g. 13C, 15N), hormones, fluoride, environmental pollutants e.g. arsenic, have also been detected and quantified from the nail plate $[15,16]$. At the same time, water 
is constantly being lost from the body into the outside environment through the nail plate, and transonychial water loss values ranging from 7 to $75 \mathrm{~g} / \mathrm{m}^{2} \mathrm{~h}$ have been reported [17-24].

Despite the considerable body of literature on various properties of the nail plate as described above, the nail plate's pH (unlike the skin's pH) has not been investigated. $\mathrm{pH}$ is normally defined as the logarithm of the reciprocal of the activity of free hydrogen ions in a solution. Obviously, this definition cannot be directly applied for nail plate or skin $\mathrm{pH}$. Despite this difficulty in $\mathrm{pH}$ definition, skin $\mathrm{pH}$ has been extensively measured, and such investigations are contributing to a greater understanding of the skin physiology and pathology. The skin surface $\mathrm{pH}$ has been found to be acidic, to be able to resist an acidic/alkaline aggression to some extent, and to be influenced by factors such as age, anatomical site, skin moisture, sebum, sweat, skin irritants, and certain diseases [25-33]. The skin's surface pH is most commonly measured potentiometrically and this technique is explained by Welzel [34]. A hydrated planar glass electrode connected to a pH meter is placed on the skin. Subsequently, water-soluble components of the stratum corneum (SC) are extracted out of the $\mathrm{SC}$ and into the liquid interface between the skin and the $\mathrm{pH}$ measuring probe. The $\mathrm{pH}$ of this solution is then read by the glass electrode and gives an indication of the $\mathrm{pH}$ of the skin surface. As the $\mathrm{pH}$ value thus obtained is due to the extraction of water-soluble components out of the stratum corneum, it has been proposed that the value is an apparent $\mathrm{pH}$, which should be interpreted with caution [35]. In order to overcome the obvious difficulty of $\mathrm{pH}$ definition as mentioned above, some researchers have introduced a specific definition: skin surface $\mathrm{pH}$ being defined as the $\mathrm{pH}$ measured by a flat glass electrode at the skin surface with a hydrated skin-electrode interface [25].

In order to address the lack of knowledge on the nail plate $\mathrm{pH}$, we measured it potentiometrically in the same way as skin $\mathrm{pH}$ is measured i.e. by placing a hydrated planar glass electrode against the nail plate. It is expected that water-soluble components of the nail plate such as fatty acids mentioned above would be extracted into the liquid interface between the nail plate and the glass electrode, and that the $\mathrm{pH}$ of this solution would give an indication of the nail plate $\mathrm{pH}$. The latter suffers from the same difficulties as skin $\mathrm{pH}$, such as that of the normal definition of $\mathrm{pH}$, and likewise, must be regarded as an apparent $\mathrm{pH}$, and applied with caution. However, further studies into nail plate $\mathrm{pH}$ might show a possible role in its health and susceptibility to disease. For example, the $\mathrm{pH}$ of the nail plate surface might influence its resident and opportunistic microflora and subsequent development of infections such as onychomycosis.

\section{MATERIALS AND METHODS}

Design

The study was a prospective, non-blinded, non-medicated study on healthy volunteers and was approved by the London School of Pharmacy's ethics committee. 
Study population

Thirty seven volunteers (16 females and 21 males, aged 22-69 years old) with healthy nails participated in the study after having given written, informed consent. All the volunteers did not participate in every part of the study; the number of volunteers who participated in each part of study is indicated in the Results Section.

Measurements

All measurements were performed in an air-conditioned room where the temperature ranged from $20.1{ }^{\circ} \mathrm{C}$ to $25.2{ }^{\circ} \mathrm{C}$ (mean $22.8 \pm 1.1{ }^{\circ} \mathrm{C}$ ), and the relative humidity ranged from $22 \%$ to $35 \%$ (mean $28.0 \pm 3.4 \%$ ). These ambient conditions are different to those prescribed by the EEMCO guidance for the measurement of skin $\mathrm{pH}$ [26], which proposes desirable conditions of $20-22{ }^{\circ} \mathrm{C}$ (to minimise sweat production) and relative humidity $(\mathrm{RH})$ of between 40 and $60 \%$. Fortunately the nail plate is not subject to sweating like the skin, and the slightly higher experimental temperature is unlikely to influence the $\mathrm{pH}$ measurement to any significant extent. Any influence of the lower experimental $\mathrm{RH}$ on nail $\mathrm{pH}$ is harder to predict and will have to be investigated in future studies.

Nail plate $\mathrm{pH}$ was measured using the skin pH meter $\mathrm{PH} 905^{\circledR}$ (Courage and Khazaka $\mathrm{GmbH}$, Germany)s, which consists of a flat glass probe combining measurement and reference electrode in a single probe. The instrument was calibrated using $\mathrm{pH}$ buffers 4.0 and 7.0 at the beginning of each day. For every measurement, the probe was rinsed with distilled water and applied at right angle to the nail plate with gentle pressure for about one minute before the $\mathrm{pH}$ was read. Multiple readings were taken to ensure the $\mathrm{pH}$ had stabilised and the stable $\mathrm{pH}$ value was then recorded.

Measurement of the nail plate surface $\mathrm{pH}$ using a flat glass $\mathrm{pH}$ probe presented some challenges. Firstly, the equipment had been designed for the skin, which offers a large area and a soft nature compared to the nail plate. The hardness of the nail plate meant that a perfectly good interface could not be created between the nail plate and the flat glass probe. In addition, some nail plates' area was too small to allow measurement. Nevertheless, it was possible to measure the nail plate $\mathrm{pH}$ in many, but not all, individuals recruited for the study. The nail plates were too curved in one female and too ridged in one male to allow optimal contact with the flat glass probe for successful measurement. When optimal contact between the nail plate and the flat glass probe was achieved, measurement of the $\mathrm{pH}$ of all the fingernails and the two big toenails was attempted. This was not always possible; some fingernails, especially the little fingernail, were often too curved and/or too small. Similarly, only the big toenails could be measured; the other toenails did not offer a sufficiently large area for placement of the $\mathrm{pH}$ probe.

Another challenge was the fact that nail plates, especially of the hands, are regularly washed after routine daily activities. Although it is known that washing alters skin $\mathrm{pH}$, 
and is influenced by the nature of the cleansing agent, in this first study on nail plate $\mathrm{pH}$, it was not feasible to ask volunteers to abstain from handwashing for a number of hours (the number being unknown at the time) prior to participating in the study. To mitigate for this, the pH of 'unwashed' (i.e. as presented by the volunteers) as well as of 'washed' nails where the washing procedure was controlled was measured.

Measurement of unwashed nails.

Volunteers rested in the room for 20 minutes prior to any measurements. The $\mathrm{pH}$ of the nail plates was then measured as described above.

Influence of washing, and measurement of washed nails.

To investigate the influence of washing, volunteers washed their hands with tap water and Cussons Carex ${ }^{\circledR}$ (sensitive) handwash (whose pH was 4.02), and blotted them dry using paper towels. The nail plate $\mathrm{pH}$ was immediately measured as described above. In some volunteers, $\mathrm{pH}$ measurement was continued, to investigate for changes in $\mathrm{pH}$ with time. It was found that following washing, the nail plate $\mathrm{pH}$ stabilised within 20 minutes. Subsequently, a larger study was conducted to measure the $\mathrm{pH}$ of washed finger and toe nail plates, where the volunteers washed their hands and feet as described above, and rested in the room for 20 minutes before nail plate $\mathrm{pH}$ was measured.

Measurement of the $\mathrm{pH}$ of the nail plate interior

This study was conducted on unwashed, as well as washed and rested (for 20 minutes) nails. In order to determine the pH inside the nail plates, the surface layers of the two thumb nailplates were removed by tape stripping using D-Squame adhesive discs (diameter $14 \mathrm{~mm}$, Cuderm, Dallas, USA). The thumb was chosen as it provided the flattest and largest surface for $\mathrm{pH}$ measurement. Following measurement of nail plate $\mathrm{pH}$ (the pre-stripping control value), an adhesive disc was placed on top of the nail plate, and firmly pressed by the operator for 30 seconds before being removed. The procedure was repeated a number of times, and the $\mathrm{pH}$ of the newly exposed nail plate surface was measured after every ten strips, except in one volunteer who received a total of 15 strips. The number of tape strips used depended on the volunteers' comfort, as tape stripping was stopped when the volunteer felt tingling and discomfort at the nail. Thus, in the unwashed nails group, the different volunteers received a total of either 15 ( 1 volunteer), 20 (1 volunteer), 30 (2 volunteers), 40 (1 volunteer) or 50 (1 volunteer) strippings. In the washed nails group, the volunteers received a total of either 15 (1 volunteer), 20 (5 volunteers), 30 (1 volunteer) and 40 (3 volunteers) tape strippings.

Statistics

To investigate the influence of gender, anatomical site (finger or toe nails) and side (left/right) on the nail plate $\mathrm{pH}$, general linear model was performed. Repeated measures ANOVA were conducted to investigate differences, if any, among the fingernails. Paired t tests were used to investigate the influence of handwashing on the nail plate $\mathrm{pH}$ and to compare the $\mathrm{pH}$ of the nail plate surface and that of its interior. 
Independent $t$ tests were conducted to investigate differences, if any, between the $\mathrm{pH}$ of unwashed and washed finger and toe nail plates in males and females. SPSS 18 was used for all statistical calculations.

\section{RESULTS}

\section{pH of unwashed nail plate surface}

The mean $( \pm s d) \mathrm{pH}$ of the surface of unwashed nail plates was $5.0 \pm 0.5$, with a minimum of 3.4 and a maximum of 6.3 measured in 157 fingernails and 33 big toenails in 15 males and 13 females. To investigate the influence of gender, anatomical site (finger or toe nails) and side (left/right) on the nail plate $\mathrm{pH}$, general linear model was performed. Gender and anatomical site were found to have significant influences on $\mathrm{pH}(\mathrm{p}<0.01)$ while side had no influence $(\mathrm{p}=0.2)$. The nail plate $\mathrm{pH}$ was higher in males and in toenails as shown in Table 1 . In 15 volunteers, it had been possible to measure all ten fingernails. Repeated measures ANOVA, conducted to investigate differences, if any, among the fingernails, showed no significant difference among the $\mathrm{pH}$ of the ten digits $(p>0.01)$.

\section{pH of washed nail plate surface}

In order to remove the possible influence of extraneous substances such as residual cosmetics on the nail plate $\mathrm{pH}$, nails were washed. Immediately after handwashing and drying, the $\mathrm{pH}$ of the fingernail surface increased, from a mean \pm sd of $5.1 \pm 0.4$ to 5.3 \pm 0.5 (paired t test, $p<0.01, n=140$ fingernails in 14 volunteers). The raised $\mathrm{pH}$ was however not sustained with time, as shown in Figure 1. Within 20 minutes of washing, the $\mathrm{pH}$ had decreased to pre-washing levels.

Subsequently, a larger study was conducted to measure the $\mathrm{pH}$ of washed, dried and rested (for at least 20 minutes) finger- and toe- nail plates. The mean ( $\pm s d) \mathrm{pH}$ of the surface of washed nail plates was $5.1 \pm 0.6$, with a minimum of 3.9 and a maximum of 6.9 measured in 204 fingernails and 32 big toenails in 13 males and 9 females. Once more, general linear model was performed to investigate the influence of gender, anatomical site (finger or toe nails) and side (left/right) on the nail plate $\mathrm{pH}$. In washed nails, only the anatomical site was found to have a significant influence on $\mathrm{pH}(\mathrm{p}=0.01)$ while side and gender had no influence $(\mathrm{p}>0.2)$. The $\mathrm{pH}$ of toenail plates was higher than that of fingernail plates (Table 1). Once again, it had been possible to measure all ten fingernails in 15 volunteers; repeated measures ANOVA showed no significant difference among the $\mathrm{pH}$ of the ten digits $(\mathrm{p}=0.2)$.

Independent $\mathrm{t}$ tests conducted to investigate differences, if any, between the $\mathrm{pH}$ of unwashed and washed (and rested) finger and toe nail plates in males and females (Table 1) showed no significant influence of washing, when the latter is accompanied by resting for at least 20 minutes ( $p \geq 0.5)$, except for the fingernails in females $(p<0.01)$. Females' washed fingernails had a significantly higher $\mathrm{pH}$ than unwashed ones. 


\section{$\mathrm{pH}$ of the nail plate interior}

Tape stripping removes nail plate cells, as shown in Figure 2. Sequential tape stripping of the nail plate caused some discomfort to the volunteers who felt a tingling sensation at the nail, once a certain number of strippings had been performed, and the newly exposed nail plate surface was seen to be somewhat 'flaky' (Figure 3). Different volunteers could tolerate different numbers of tape strips before they complained of discomfort and before the newly exposed nail plate surface became 'flaky' (Figure 3). It appears that different amounts of nail cells/layers are removed per tape strip in the different volunteers as a result of inherent inter-individual nail plate variability. Such inter-individual variability reflects results by Tudela et al 2008 who reported variable amounts of nail protein removed in different individuals following 20 tape strips in each volunteer [24].

As the number of tape strippings tolerated, and therefore performed, on the volunteers varied, the pre-stripping $\mathrm{pH}$ and the final $\mathrm{pH}$ for each volunteer were compared to investigate for differences, if any, between the surface and interior nail plate $\mathrm{pH}$. For unwashed nails, a statistically significant difference (paired t test, $p<0.05 ; n=12$ thumbnails in 6 volunteers) was found, with the $\mathrm{pH}$ of the nail plate interior $(4.1 \pm 0.7)$ being lower than that of its surface $(4.7 \pm 0.7)$. For washed nails (20 thumbnails in ten volunteers), the $\mathrm{pH}$ of the nail plate interior was also lower $(4.8 \pm 0.6)$ than that at its surface which were $5.1 \pm 0.5$ (before washing) and $5.2 \pm 0.7$ (after washing and resting).

\section{DISCUSSION \\ Nail plate $\mathrm{pH}$}

It was possible to measure the $\mathrm{pH}$ of most (but not all) fingernail and big toenail plates' surface using a hydrated planar glass electrode, despite some challenges, such as the nail plate's curvature and small area. The $\mathrm{pH}$ value thus obtained is likely to be due to the extraction of water-soluble components of the nail plate into the liquid interface between the nail plate and the $\mathrm{pH}$ measuring probe, as well as, the presence of sweat and sebum (from contact between skin and nail or possibly sebum/sweat flow from surrounding skin onto the nail plate), and, especially in unwashed nails, residual cosmetics such as hand creams. Hence, the $\mathrm{pH}$ value measured on the nail plate surface is an apparent $\mathrm{pH}$, and should be interpreted with caution, as has been advised for skin $\mathrm{pH}$ measurements $[26,35]$. As mentioned in the Introduction, the nail plate constituents include proteins, mucopolysaccharides, water, lipids [2][12][13, 14]. It is feasible that some of the water-soluble nail plate components are extractable and contribute to a reading of nail plate surface $\mathrm{pH}$ when the latter is measured with a hydrated glass electrode.

The $\mathrm{pH}$ of the nail plate surface was found to be acidic (Table 1). This reflects the acidic surface of the skin, whose usual pH is reported to lie between 4 and 6 [26]. In our own study, the forearm and midfoot skin $\mathrm{pH}$ of nineteen volunteers was measured and was found to be $5.0 \pm 0.6$ and $4.9 \pm 0.8$ respectively. It is possible that the acidic $\mathrm{pH}$ of the 
nail plate surface plays a role in antimicrobial defence, acidic $\mathrm{pH}$ being known to be bacteriostatic and fungistatic for certain strains.

No statistical difference was found among the $\mathrm{pH}$ of the nail plates of the five fingers, between the right and left hands, and between the right and left feet. This could have expected due to the similar functions and environments experienced by the ten fingernails and by the two toenails.

\section{Higher toenail plate $\mathrm{pH}$ compared to fingernail $\mathrm{pH}$}

Toenail $\mathrm{pH}$ was statistically higher than fingernail $\mathrm{pH}$ for both washed and unwashed nails (Table 1). It is unclear why this should be so, as differences between the properties of finger- and toe- nails have not been systematically investigated to any great extent. From the limited literature, it is known that toenail plates are thicker and grow at a slower rate compared to fingernails [36]. The thicker toenails allow a smaller transonychial water loss than the fingernails [22]. It is interesting though, to note that the higher toenail $\mathrm{pH}$ (compared to fingernail $\mathrm{pH}$ ) reflects the statistically higher foot skin $\mathrm{pH}$ compared to hand skin $\mathrm{pH}$ reported in a small cohort of Japanese men [37].

Although the reason for the higher toenail $\mathrm{pH}$ is unclear, it may have medical significance. If the acidic nature of the nail plate does have a role in antimicrobial defence, the lower acidity of toenail plate (compared to the fingernails) might contribute to their greater susceptibility to infections. Indeed, a higher incidence of onychomycosis [38], greater recalcitrance to treatment and the need for longer treatment duration in toenails compared to fingernails is well known [39]. The higher toenail $\mathrm{pH}$ might also favour the production of fungal arthroconidia (drug resistant dormant fungal spores which can germinate months after cessation of therapy and reinfect the nail [40]), whose production by Trichophyton rubrum-one of the most common fungal causes of onychomycosis - was shown in vitro to be dependent on the $\mathrm{pH}$ of the medium, increasing from $\mathrm{pH} 4.5$ to $\mathrm{pH} \mathrm{7.5,} \mathrm{and} \mathrm{decreasing} \mathrm{thereafter} \mathrm{[41].}$

\section{Influence of gender on nail plate $\mathrm{pH}$}

Gender influenced the $\mathrm{pH}$ of unwashed nails, but not that of washed ones. This indicates that the lower $\mathrm{pH}$ in females' unwashed nails was due to an exogenous factor, such as residual hand creams. Use of cosmetics such as moisturizers has been suggested as a potential reason for reported differences in skin $\mathrm{pH}$ between males and females and for the conflicting reports on the influence of gender on skin pH [42].

Further studies where volunteers refrain from using topical products on the hands and feet and use the same cleansers for washing, for a run-in phase prior to measurement of 'unwashed' nail plate $\mathrm{pH}$ could resolve the influence of gender on nailplate $\mathrm{pH}$.

\section{Influence of washing on nail plate $\mathrm{pH}$}

Washing caused a transient increase in the $\mathrm{pH}$ of the nail plate surface. This reflects the increase in skin $\mathrm{pH}$ following washing, even with only tap water [43, 44]. Although the liquid cleanser used had a $\mathrm{pH}$ of 4.02 , the $\mathrm{pH}$ of the washing solution (cleanser + tap 
water) encountered by the nail plates was much higher and close to that of tap waterthe $\mathrm{pH}$ of a $2 \% \mathrm{w} / \mathrm{w}$ aqueous solution of the cleanser in tap water was found to be 7.90 . This high $\mathrm{pH}$ medium encountered by the nail plate immediately prior to $\mathrm{pH}$ measurement might explain the change in nail surface measured $\mathrm{pH}$. As for skin $\mathrm{pH}$, the measured $\mathrm{pH}$ returns to pre-washing levels with time.

\section{Lower $\mathrm{pH}$ of nail plate interior}

The $\mathrm{pH}$ of the nail plate interior was lower than that of its surface. This could be due to enhanced extraction of acidic, water-soluble nail components during the $\mathrm{pH}$ measurement, once the topmost nail layers had been removed by tape stripping. The topmost layer of the nail plate is known to be the least permeable part of the nail plate and its removal results in increased permeation of chemicals into the nail plate [45]. Similarly, removal of the topmost nail layer is expected to increase the movement of molecules out of the bulk of the nail plate and into the liquid interface between the nail plate and the $\mathrm{pH}$ measuring probe. A decrease in nail plate $\mathrm{pH}$ upon tape stripping reflects the initial reduction in skin $\mathrm{pH}$ upon tape stripping that has been observed prior to an increase in skin pH upon further tape stripping [46-49]. The initial decrease in skin $\mathrm{pH}$ could also be the result of greater extraction of stratum corneum components once its topmost layer has been removed by tape stripping.

\section{CONCLUSIONS}

The $\mathrm{pH}$ of the nail plate surface was measured to be around 5, with toenails having significantly higher $\mathrm{pH}$ than fingernails. There was no difference however, among the ten fingernails and between the two great toenails. Gender influenced the $\mathrm{pH}$ of unwashed nails - with women having lower $\mathrm{pH}$ compared to men - but had no influence on the $\mathrm{pH}$ of washed ones, suggesting the influence of an exogenous factor. Washing the nails with a liquid cleanser and tapwater transiently increased $\mathrm{pH}$, which subsequently returned to pre-washing values within 20 minutes. Tape stripping the nail plates in order to measure the $\mathrm{pH}$ of the nail plate interior revealed a lower $\mathrm{pH}$ inside the nail plate compared to its surface.

This study has shown that it is possible to measure the surface $\mathrm{pH}$ of nail plates using the Courage \& Khazakha skin pH meter, although a long stabilisation time is needed, and the small area and high curvature of some nail plates do not allow measurement. Further work is needed to understand the role of the acidic $\mathrm{pH}$ of the nail plate in health and disease, including the reasons for and the significance of the toenail's higher $\mathrm{pH}$.

\section{ACKNOWLEDGEMENTS}

The authors are deeply grateful to all the volunteers. 


\section{REFERENCES}

1. Baden HP: PHYSICAL PROPERTIES OF NAIL. Journal of Investigative Dermatology 1970; 55(2): 115-\&.

2. de Berker D and Forslind B, The structure and properties of nails and periungual tissues, in Skin, Hair, and Nails, Structure and Function, B Forslind, Linberg, M., Norlén, L., Editor. 2004, Marcel Dekker: New York. p. 409-464.

3. Lewis BL: Microscopic studies of fetal and mature nail and surrounding soft tissue. AMA Arch Derm Syphilol 1954; 70(6): 733-47.

4. Jarrett A and Spearman RI: Histochemistry of human nail Archives of Dermatology 1966; 94(5): 652-\&.

5. Sowa MG, Wang J, Schultz CP, Ahmed MK, and Mantsch HH: Infrared spectroscopic investigation of in-vivo and ex-vivo human nails Vibrational Spectroscopy 1995; 10(1): 49-56.

6. Forslind B and Thyresson N: Structure of normal nail-scanning electronmicroscope study Archiv Fur Dermatologische Forschung 1975; 251(3): 199-204.

7. Achten G, Andre J, and Laporte M: Nails in light and electron- microscopy. Seminars in Dermatology 1991; 10(1): 54-64.

8. Rice RH, Xia Y, Alvarado RJ, and Phinney BS: Proteomic analysis of human nail plate. J Proteome Res 2010; 9(12): 6752-8.

9. Gniadecka M, Nielsen OF, Christensen DH, and Wulf HC: Structure of water, proteins, and lipids in intact human skin, hair, and nail. Journal of Investigative Dermatology 1998; 110(4): 393-398.

10. Stern DK, Diamantis S, Smith E, Wei HC, Gordon M, Muigai W, Moshier E, Lebwohl M, and Spuls P: Water content and other aspects of brittle versus normal fingernails. Journal of the American Academy of Dermatology 2007; 57(1): 3136.

11. Egawa M, Ozaki Y, and Takahashi M: In vivo measurement of water content of the fingernail and its seasonal change. Skin Research and Technology 2006; 12(2): 126-132.

12. Helmdach M, Thielitz A, Ropke EM, and Gollnick H: Age and sex variation in lipid composition of human fingernail plates. Skin Pharmacology and Applied Skin Physiology 2000; 13(2): 111-119.

13. Vellar OD: Composition of human nail substance. American Journal of Clinical Nutrition 1970; 23(10): 1272-\&.

14. Sirota L, Straussberg R, Fishman P, Dulitzky F, and Djaldetti M: X-ray microanalysis of the fingernails in term and preterm infants. Pediatric Dermatology 1988; 5(3): 184-186.

15. Wilhelm M, Pesch B, Wittsiepe R, Jakubis P, Miskovic P, Keegan T, Nieuwenhuijsen MJ, and Ranft U: Comparison of arsenic levels fingernails with urinary As species as biomarkers of arsenic exposure in residents living close to a coal-burning power plant in Prievidza District, Slovakia. Journal of Exposure Analysis and Environmental Epidemiology 2005; 15(1): 89-98.

16. Nardoto GB, Silva S, Kendall C, Ehleringer JR, Chesson LA, Ferraz ESB, Moreira MZ, Ometto J, and Martinelli LA: Geographical patterns of human diet 
derived from stable-isotope analysis of fingernails. American Journal of Physical Anthropology 2006; 131(1): 137-146.

17. Spruit D: Effect of nail polish on the hydration of the fingernail Amer. Cosmet. Perf . 1972; 87(57-58.

18. Spruit D: Measurement of Water Vapor Loss through Human Nail in-Vivo. Journal of Investigative Dermatology 1971; 56(5): 359-361.

19. Jemec GBE, Agner T, and Serup J: Transonychial water-loss - relation to sex, age and nail-plate thickness British Journal of Dermatology 1989; 121(4): 443-446.

20. Nuutinen J, Harvima I, Lahtinen MR, and Lahtinen T: Water loss through the lip, nail, eyelid skin, scalp skin and axillary skin measured with a closed-chamber evaporation principle. British Journal of Dermatology 2003; 148(4): 839-841.

21. Kronauer C, Gfesser M, Ring J, and Abeck D: Transonychial water loss in healthy and diseased nails. Acta Dermato-Venereologica 2001; 81(3): 175-177.

22. Murdan S, Hinsu D, and Guimier M: A few aspects of transonychial water loss (TOWL): Inter-individual, and intra-individual inter-finger, inter-hand and interday variabilities, and the influence of nail plate hydration, filing and varnish. European Journal of Pharmaceutics and Biopharmaceutics 2008; 70(2): 684-689.

23. Dutet J and Delgado-Charro MB: In vivo transungual iontophoresis: Effect of DC current application on ionic transport and on transonychial water loss. Journal of Controlled Release 2009; 140(2): 117-125.

24. Tudela E, Lamberbourg A, Diaz MC, Zhai H, and Maibach HI: Tape stripping on a human nail: quantification of removal. Skin Research and Technology 2008; 14(4): 472-477.

25. Fluhr J, Bankova L, and Dikstein S, Skin surface pH: mechanism, measurement, importance, in Handbook of non-invasive methods and the skin, GJ J Serup, GL Grove, Editor. 2006. p. 411-427.

26. Parra JL, Paye M, and Grp E: EEMCO guidance for the in vivo assessment of skin surface pH. Skin Pharmacology and Applied Skin Physiology 2003; 16(3): 188-202.

27. Schmid-Wendtner $\mathrm{MH}$ and Korting HC: The $\mathrm{pH}$ of the skin surface and its impact on the barrier function. Skin Pharmacology and Physiology 2006; 19(6): 296-302.

28. Rippke F, Schreiner V, and Schwanitz H-J: The acidic milieu of the horny layer: new findings on the physiology and pathophysiology of skin $\mathrm{pH}$. Am J Clin Dermatol 2002; 3(4): 261-72.

29. Schreml S, Szeimies RM, Karrer S, Heinlin J, Landthaler M, and Babilas P: The impact of the $\mathrm{pH}$ value on skin integrity and cutaneous wound healing. Journal of the European Academy of Dermatology and Venereology 2010; 24(4): 373-378.

30. Waller JM and Maibach HI: Age and skin structure and function, a quantitative approach (I): blood flow, $\mathrm{pH}$, thickness, and ultrasound echogenicity. Skin Research and Technology 2005; 11(4): 221-235.

31. Agache P, Presentation of the Skin Surface Ecosystem, in Measuring the Skin, $P$ Agache and P Humbert, Editors. 2004, Springer-Verlag: Berlin. p. 21-32.

32. Agache P, Measurement of Skin Surface Acidity, in Measuring the Skin, $\mathrm{P}$ Agache and P Humbert, Editors. 2004, Springer: Berlin. p. 84-86.

33. Levin J and Maibach H: Human skin buffering capacity: an overview. Skin Research and Technology 2008; 14(2): 121-126. 
34. Welzel J, pH and ions, in Bioengineering of the skin: methods and instrumentation, PE E Berardesca, KP Wilhelm, HI Maibach, Editor. 1995, CRC Press: Boca Raton. p. 91-93.

35. Rieger M: The apparent $\mathrm{pH}$ of the skin. Cosmet Toiletries 1989; 104(53-60.

36. Fleckman P, Structure and Function of the Nail Unit, in Nails. Diagnosis Therapy Surgery, R Scher and CR Daniel III, Editors. 2005, Elsevier Saunders. p. 13-25.

37. Chikakane $\mathrm{K}$ and Takahashi $\mathrm{H}$ : Measurement of skin $\mathrm{pH}$ and its significance in cutaneous diseases. Clinics in Dermatology 1995; 13(4): 299-306.

38. Midgley G, Moore, M.K., Cook, J.C: Mycology of nail disorders. Journal of the American Academy of Dermatology 1994; 31 (S68-S74.

39. BNF, ed. British National Formulary. 56 ed. 2008, BMJ Group \& RPS Publishing: London.

40. Arrese JE and Pierard GE: Treatment failures and relapses in onychomycosis: A stubborn clinical problem. Dermatology 2003; 207(3): 255-260.

41. Yazdanparast SA and Barton RC: Arthroconidia production in Trichophyton rubrum and a new ex vivo model of onychomycosis. J Med Microbiol 2006; 55(Pt 11): 1577-81.

42. Burry JS, Coulson HF, Esser I, Marti V, Melling SJ, Rawlings AV, Roberts G, and Mills AK: Erroneous gender differences in axillary skin surface/sweat $\mathrm{pH}$. International Journal of Cosmetic Science 2001; 23(2): 99-107.

43. Gfatter R, Hackl P, and Braun F: Effects of soap and detergents on skin surface $\mathrm{pH}$, stratum corneum hydration and fat content in infants. Dermatology 1997; 195(3): 258-262.

44. Korting HC, Kober M, Mueller M, and Braunfalco O: INFLUENCE OF REPEATED WASHINGS WITH SOAP AND SYNTHETIC DETERGENTS ON PH AND RESIDENT FLORA OF THE SKIN OF FOREHEAD AND FOREARM - RESULTS OF A CROSSOVER TRIAL IN HEALTHY PROBITIONERS. Acta Dermato-Venereologica 1987; 67(1): 41-47.

45. Kobayashi Y, Miyamoto M, Sugibayashi K, and Morimoto Y: Drug permeation through the three layers of the human nail plate. Journal of Pharmacy and Pharmacology 1999; 51(3): 271-278.

46. Wilhelm D, Elsner P, and Maibach HI: STANDARDIZED TRAUMA (TAPE STRIPPING) IN HUMAN VULVAR AND FOREARM SKIN - EFFECTS ON TRANSEPIDERMAL WATER-LOSS, CAPACITANCE AND PH. Acta Dermato-Venereologica 1991; 71(2): 123-126.

47. Berardesca E, Pirot F, Singh M, and Maibach H: Differences in stratum corneum $\mathrm{pH}$ gradient when comparing white Caucasian and black African-American skin. British Journal of Dermatology 1998; 139(5): 855-857.

48. Wagner H, Kostka KH, Lehr CM, and Schaefer UF: pH profiles in human skin: influence of two in vitro test systems for drug delivery testing. European Journal of Pharmaceutics and Biopharmaceutics 2003; 55(1): 57-65.

49. Ohman H and Vahlquist A: IN-VIVO STUDIES CONCERNING A PH GRADIENT IN HUMAN STRATUM-CORNEUM AND UPPER EPIDERMIS. Acta Dermato-Venereologica 1994; 74(5): 375-379. 


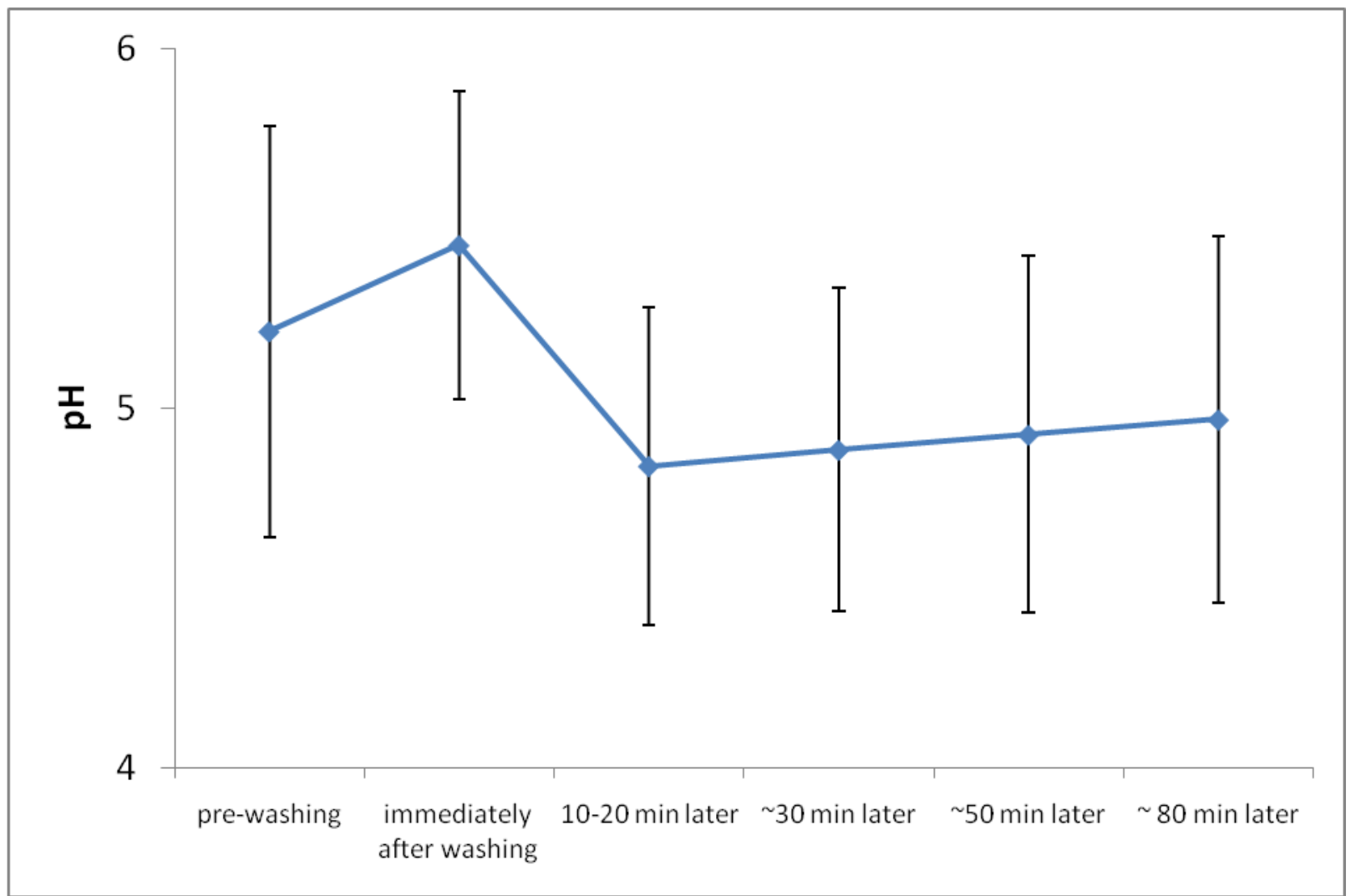

Figure 1: Change in nail plate surface $\mathrm{pH}$ upon washing and subsequently with time. The latter is given as an approximation, rather than a definite value as the time varied slightly for each volunteer and for each nail, depending on the durations of $\mathrm{pH}$ measurements. 


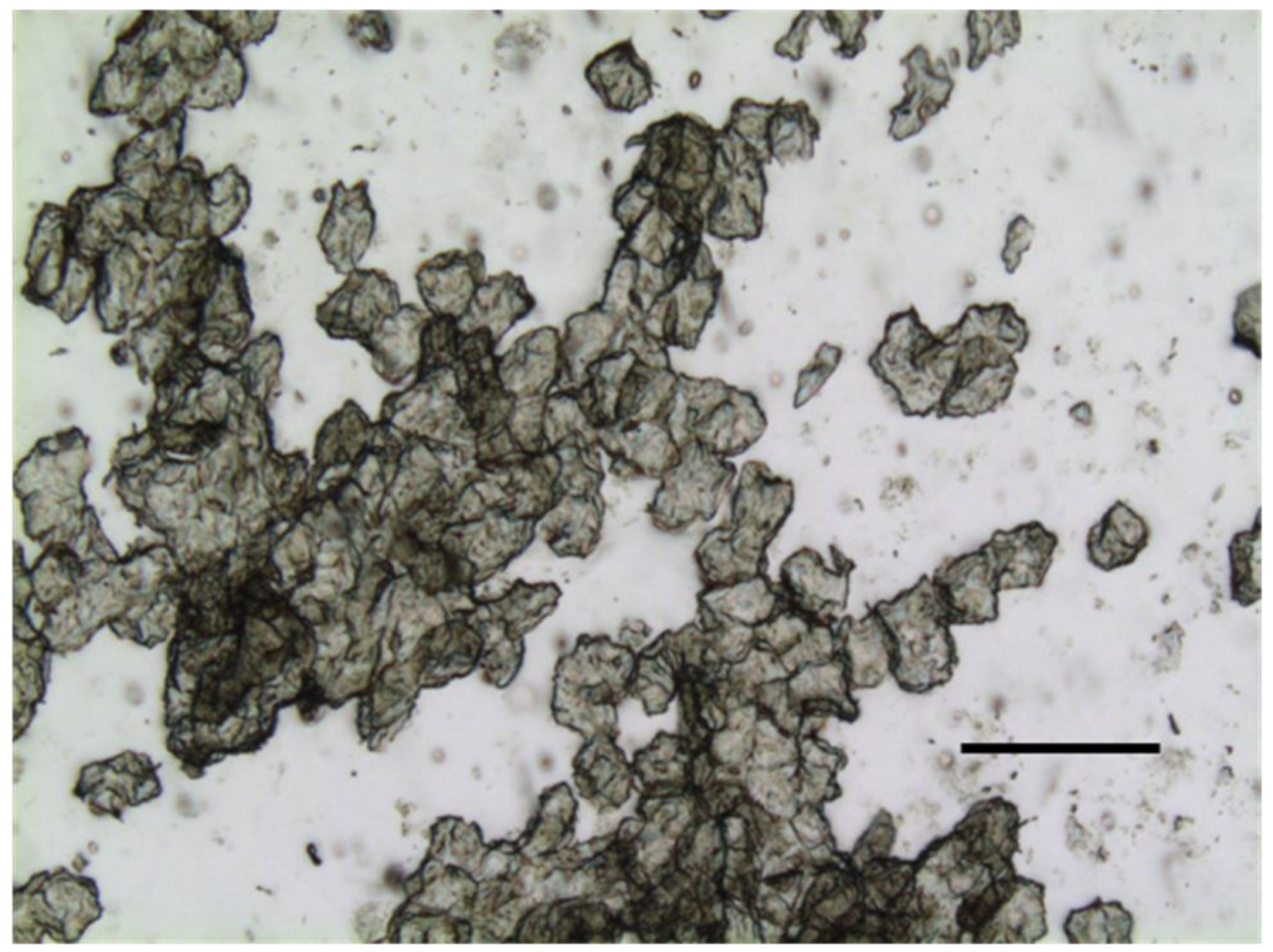

Figure 2: Light micrograph shows nail plate cells on an adhesive tape, following tape stripping of a nail plate. Bar represents $100 \mu \mathrm{m}$. 


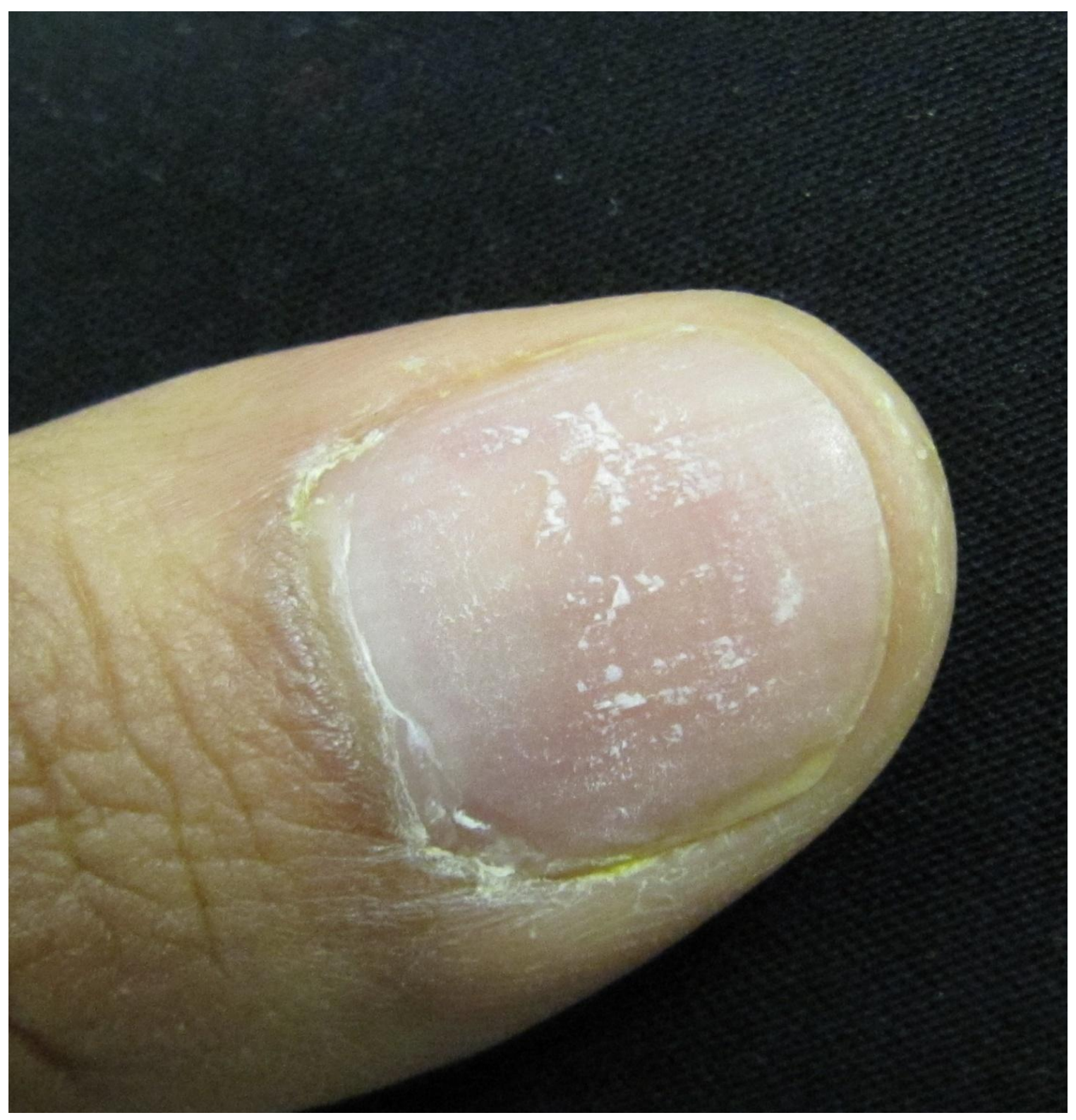

Figure 3: The 'flaky' appearance of the nail plate surface after tape stripping. This volunteer received a total of 15 tape strips, at which point he felt discomfort and tingling. 
Table 1: Measured $\mathrm{pH}$ of unwashed and washed finger- and toe- nailplate surface in males and females

\begin{tabular}{|c|c|c|c|c|}
\hline \multirow{3}{*}{ Gender } & \multicolumn{4}{|c|}{$\begin{array}{l}\mathrm{pH} \text { of nail plate surface } \\
\text { mean } \pm \text { SD } \\
\text { (minimum-maximum; } \mathrm{N}=\text { number of nails in } \mathrm{n}=\text { number of volunteers) }\end{array}$} \\
\hline & \multicolumn{2}{|c|}{ Unwashed nails } & \multicolumn{2}{|c|}{ Washed and rested nails } \\
\hline & Fingernails & toenails & Fingernails & toenails \\
\hline Males & $\begin{array}{l}5.1 \pm 0.5 \\
(3.4-6.1 ; N=87 \\
\text { in } n=10)\end{array}$ & $\begin{array}{l}5.3 \pm 0.4 \\
(4.5-6.3 ; N=20 \\
\text { in } n=10)\end{array}$ & $\begin{array}{l}5.1 \pm 0.5 \\
(3.9-6.4 ; N=125 \\
\text { in } n=13)\end{array}$ & $\begin{array}{l}5.3 \pm 0.7 \\
(4.1-6.9 ; N=20 \\
\text { in } n=11)\end{array}$ \\
\hline Females & $\begin{array}{l}4.8 \pm 0.4 \\
(3.8-5.7 ; N=70 \\
\text { in } n=7)\end{array}$ & $\begin{array}{l}5.4 \pm 0.5 \\
(4.4-5.8 ; N=13 \\
\quad \text { in } n=7)\end{array}$ & $\begin{array}{l}5.1 \pm 0.6 \\
(3.9-6.5 ; N=79 \\
\quad \text { in } n=9)\end{array}$ & $\begin{array}{l}5.6 \pm 1.0 \\
(4.7-6.9 ; N=13 \\
\text { in } n=7)\end{array}$ \\
\hline
\end{tabular}

